\title{
EXERCISE IN THE REHABILITATION OF CHD PATIENTS $\dagger$
}

\author{
T. Noakes M.B. Ch.B. MD (UCT)*
}

\section{SUMMARY}

The author sets out to show why cardiac patients should follow an exercise regimen and that the important psichological benefits achieved by an exercise rehabilitation programme relate to the healing concept - to making the patient whole again. In addition the capacity for physical work increases as does the "angina ihreshold". The safelv of the patient is ensured bl' prescribing exercise based on results of the target heart raie concept. Finally the author defends walking and jogging as the ideal mode of exercise.

\section{INTRODUCTION}

In the past decade a wealth of information has accumulated showing that following heart attack or coronary artery bypass surgery, cardiac patients derive specific benefits from carefully prescribed programmes of graduated exercise (Pollock, M. L. and Schmidt, D. H. (1979)). Such programmes consist ideally of three separate phases:-

- the acute in-hospital phase beginning as soon as the patient is admitted to a hospital Intensive Coronary Care Unit with acute myocardial infarction;

- a hospital-based programme in which mild, graded exercise usually involving circuit training on apparatus is performed in a hospital out-patient department and;

- participation in a more vigorous, community-based exercise programme commencing some 9-12 weeks after myocardial infarction.

This article will concentrate specifically on the methodology and philosophy of community-based exercise rehabilitation programmes. It is the author's contention that medical ignorance of, and indeed frank disinterest in the value such programmes can play in the psychological and physiological repair of cardiac patients (Pollock, M. L. and Schmidt, D. H. (1979); Kavanagh, T. and Noakes, T. D. (1979)), remains a major reason why the medical care of such patients may be less than optimum.

\section{WHY CARDIAC PATIENTS DO NOT EXERCISE, AND WHY THEY SHOULD}

The most likely reason why most patients do not exercise after heart attack, is that they either receive no advice to exercise or they are specifically advised against exercising by their doctors. The rationale behind either of these approaches has been defined and discussed (Noakes, T. D. (1982)). In essence, exercise after heart-attack is held to be too dangerous, too expensive and of no proven benefit. In addition it is argued that there are no medical personnel to spare on the survivors of heart-attacks, because such

\footnotetext{
$\dagger$ Reprinted by permission of SA Sports Medicine.

${ }^{*}$ Convenor of post-graduate sports science course.
}

Metropolitan Sport Science Centre

Department of Medicine,

University of Cape Town

\section{OPSOMMING}

Die skrywer n'vs aan waarom hart pasiente 'n oefenprogram moet volg en dat die belangrike sielkundige voordele behaal deur in oefenrehabilitasieprogram in verband staan met die helingskonsep - om die pasient weer heel te maak. Daarby vermeerder die fisiese werkskapasiteil, asook die "angina drempel". Die veiligheid van clie pasient word verseker deur oefening, gebaseer op die resultate van die "mikpunt hartslag konsep". Ten slotte verdedig die skrywer stap en preldraf as die ideale metode van oefening.

personnel are already too busy looking after the acutely-ill. Each of these criticisms has been debunked elsewhere (Noakes, T. D. (1982)) and will therefore not be restated. Suffice it to say that such criticisms may reflect a serious malaise of modern medicine - namely its monopolization by so-called "curative medicine" to the total exclusion of preventive and rehabilitative medicine. One important result is that our modern "scientific" a pproach to the evaluation of a novel therapeutic intervention, such as exercise, is to evaluate that intervention exclusively on the basis of whether or not it plays a curative role in a specific disease process. Thus we demand that there must always be a scientificallytestable endpoint against which any new intervention must be evaluated; in the case of exercise after heart-attack, such exercise must be shown to reduce the re-infarction rate and increase longevity. As long as these remain the sole criteria for evaluation, then the role that exercise can play in the rehabilitation of cardiac patients will never be fully appreciated.

For the simple reason that this "scientific" attitude runs quite contrary to what should be an inviolate medical attitude namely that medicine is as much the art of healing as it is the science of curing. With regard to coronary heart disease, there is as yet no proven method by which the primary pathological process in this disease, coronary atherosclerosis, can be reversed. Nor is there any known method by which the infarcted myocardium can be restored. Thus modern medicine has little science with which to cure this disease and it is therefore illogical to expect that exercise can achieve this.

What exercise rehabilitation achieves' for the cardiac patient relates to the threatened medical art of healing. Healing is the treating of the patient's illness, which is simply the mental response to the disease. Healing is the art of decreasing symptoms, of enhancing the patient's sense of physical and psychological well-being, of restoring the whole person. Unfortunately, these changes are not easily, nor frequently, measured. They do not show on blood tests, on chest $X$-rays, on coronary angiograms, on electrocardiograms, or even on tests of heart function. Yet we would be wrong to assume that these important changes do not occur in exercising cardiac patients. For it may be that the exercise rehabilitation of the cardiac patient achieves two benefits that no doctor and no bottle of pills can.

First, exercise rehabilitation makes the patient an active and aware participant in his own recovery. Coronary disease is believed to be a lifestyle disease and successful 
rehabilitation must aim to alter the negative aspects of each patient's lifestyle. No physician can legislate an altered lifestyle for his patient. The only person who can successfully achieve that is the patient. But if the patient chooses to remain a pill-popping spectator, who continues to smoke heavily, who continues to eat incorrectly and who continues to work excessively, his prognosis must remain grave.

What the correct exercise rehabilitation programme does then, is to alter the patient's self concept. It teaches him that he must look after his body in the same way that the athlete does. He must consider how his daily habits affect his physical and mental performance. Fortunately, regular exercise provides immediate, daily feedback. If the patient over-indulges in any of the detrimental lifestyle pursuits described above, they will adversely affect his exercise capacity.

Second, exercise training shows the patient that he is not physically crippled. A fundamental component of his disease is that the cardiac patient views his disease as a physical, not a psychological disability. Thus the psychological trauma that the patient experiences after a heart attack, relates mostly to his fear that his heart attack has left him physically incapacitated (Cassem, N. H. and Hackett, T. P. (1977)). The patient knows that to live and work comfortably he must have a certain degree of myocardial integrity and a certain level of physical fitness. But exercise is the sole "test" that will show the patient that he is not a physical cripple. In contrast, if the patient does not exercise or is confined to bed for any length of time, his physical fitness will deteriorate, and he will incorrectly interpret this fall in physical fitness as evidence of impaired heart function (Cassem, N. H. and Hackett T.P. (1977)). This was the universal outcome of the outdated six weeks' bed rest treatment for myocardial infarction (Kavanagh. T and Noakes, T. D. (1979)).

In summary, the important psychological benefits achieved by an exercise rehabilitation programme relate to the healing concept - to making the patient whole again. It must be emphasized that the specific psychological benefits derived from exercise rehabilitation are sufficiently important by themselves to justify an exercise rehabilitation programme. But other important benefits do exist.

\section{ALTERATIONS IN WORK CAPACITY AND THE "ANGINA THRESHOLD"}

Physical work capacity is increased in virtually all exercise-rehabilitated cardiac patients, with the most important benefit being an alteration in the angina threshold.

Exercise training markedly increases the angina threshold so that after training, more intensive exercise can be performed before angina occurs. The mechanism for this increase in the angina threshold is probably due not to increased blood flow to the area of jeopardized (ischaemic) myocardium (Ferguson et al. (1978)). Rather it is due to a reduction in the exercising heart rate and blood pressure, and therefore in myocardial oxygen demand, mediated by adaptations specific to the trained, skeletal muscles (Clausen J. P. (1976)). The result is that, at the same external workload (i.e. walking or jogging speed), the work of the heart (measured as the heart rate/blood pressure product) is reduced. Therefore the angina threshold will increase, but because this is due not to cardiac adaptations, but principally to peripheral changes, this increase will only be apparent during exercise with the trained muscles. This "specificity of training" indicates that patients with angina must, in the first instance, be trained in the same exercise modality that causes them angina. In most cases, this will be walking.

\section{SUBSEQUENT MORTALITY OF CARDIAC PATIENTS UNDERGOING EXERCISE REHABILITATION}

Two problems cloud the question of whether or not exercise training influences subsequent mortality in coronary patients (Shephard, R. J. (1979)). First, most rehabilitation studies do not contain adequate control groups - that is, patients are not randomly assigned to an exercising or to a control group. Rather the mortality experience in the exercising group is compared to mortality in a "comparable" group.

Second, those rehabilitation programmes which have had adequate randomized control groups, have either used relatively homeopathic exercise doses or have had a poor exercise compliance record. To complicate the issue, the "non-exercising" control cardiac group has frequently become polluted with cardiac patients who take up exercise of their own accord (Shaw, L. W. (1981)). Despite these limitations, it is possible to state that

- in virtually every reported study, the mortality raf amongst exercising cardiac patients is less than in thecontrol group,

- in no studies is mortality rate in the exercising group greater than in the control group,

- studies that have failed to show any benefit for the exercising group have used a low intensity exercise, have been associated with a high drop-out rate and have been of short duration (less than 2 years). Thus the most recent data suggests that differences in mortality rates between exercising and control cardiac patients become more marked after 2 years of fairly intensive training (Shephard, R. J. (1979)).

However, more recent studies have provided more optimistic results. Thus in a carefully controlled study Kallio et al (1972) showed an almost immediate reduction in the coronary mortality of cardiac patients admitted to an intensive educational/exercise rehabilitation programme after their first heart attack. The recently reported National Exercise and Heart Disease Project (Shaw, L. W. (198I)) found evidence for a "substantial benefit from exercise" after heart attack, and Kavanagh et al (1979) reported that patients who failed to comply with an exercise rehabilitation programme after heart attack had a 22-fold higher incidence of recurrent myocardial infarction or coronary mortality than did those who continued to exercise. There was no evidence that this remarkable difference could be explaine on the basis that the most disabled patients, at high risk of recurrence, were too ill to comply with the programme. The reasons why these patients failed to continue in the exercise programme had nothing to do with progression of their disease.

But despite these considerations, my personal impression is that cardiac patients in an exercise rehabilitation programme are not greatly concerned about questions of longevity. As one cardiac patient said: "I'm not jogging to live longer. l'm jogging because it's made me fit, and I can now enjoy certain pleasures in life that have always been important to me. I no longer have angina when I stay up late at night, and I can play longer and harder than ever before, and for me that's what living is all about".

\section{INSURING THE SAFETY OF THE CARDIAC PATIENT DURING EXERCISE}

The remarkable safety of exercise rehabilitation programmes is not a chance event. Nor has it been easily achieved. It has resulted from careful attention to certain 
guidelines that have been established over the years. The following guidelines are those used by the Western Cape Cardiac Rehabilitation Programme and are based on the approach developed by Dr. Terry Kavanagh in Toronto (Kavanagh, T. and Noakes, T. D. (1979); Kavanagh, T. (1976)).

Before a cardiac patient is exposed to a regular exercise programme, it is essential that he undertake a medicallysupervised, electrocardiographically-monitored, progressive exercise (stress) test on either a bicycle ergometer or a treadmill. There are two reasons for this. First, the test will identify those patients for whom formal exercise training is contraindicted, either because they have advanced left ventricular damage or, pending therapy, because they develop serious cardiac arrhythmias during exercise. Second, the test will identify the appropriate exercise level for each patient. The following is our approach to exercise testing.

Patients who do not have any of the described contraindications to exercise testing (Pollock, M. L. and Schmidt, D. H. (1979)), are exercised on a treadmill according to either the Naughton or Balke protocol. Both these protocols are of lower intensity than is the Bruce protocol, which we feel progresses too rapidly for cardiac patients.

During the exercise test, the following parameters are monitored and recorded every minute: blood pressure via an automated system (Critikon Incorporated, Tampa. Florida), heart rate (displayed digitally), and the electrocardiogram recorded in 3 leads and displayed continuously in one lead, with a digital readout of ST levels and ST slopes in that lead (Marquette Case system; Marquette Electronics, Milwaukee, Wisconsin). In addition, the patient is carefully observed for signs, and is asked each minute to describe his level of perceived exertion (Borg, G. (1970)) and the nature of any symptoms. Respiratory gases are not analyzed during the initial test, because they only cause additional anxiety for the patient and do not providc essential information.

The exercise test is terminated when one of the following end-points is reached:

- if $85-90 \%$ of the maximum heart rate predicted for age is achieved without the patient developing either symptoms or signs of myocardial ischaemia (uncomplicated maximum test),

- if the patient develops characteristic angina pectoris (with or without compatible electrocardiographic changes), and

- if there is depression of the ST segment in any of the three monitored leads which is either horizontal or downward sloping, and in excess of $2 \mathrm{~mm}, 80$ milliseconds after the $\mathrm{J}$ point. In cardiac patients this degree of ST segment depression is highly predictive of multi-vessel disease, it indicates increased risk of a further cardiac event, and is more likely to be found in patients who have had previous inferior, rather than anterior myocardial infarction (Castellanet et al (1978); Paine et al (1978)).

- failure of either the systolic blood pressure or heart rate to increase appropriately during exercise of increasing intensity. Failure of the systolic blood pressure to rise (inotropic incompetence) is associated with exerciseinduced ventricular fibrillation (Irving, J. B. and Bruce, R. A. (1977)) and a very poor overall prognosis (Irving. J. B. and Bruce, R. A. (1977); Irving et al (1977))

- appearance of ventricular tachycardia, intracardiac block or ventricular premature beats (in excess of $25 \%$ of all beats)

- signs of excessive fatigue or dyspnoea.
On the basis of the exercise test result, it is possible to determine

- whether the patient is a candidate for an exercise rehabilitation programme or alternatively, whether he should be refcred for further cardiological evaluation, and

- at what heart rate it is safe for each patient to exercise.

PRESCRIBING EXERCISE ON THE BASIS OF THE EXERCISE TEST RESULTS - THE TARGET HEART RATE CONCEPT

In order to achieve a training effect, the exercise prescription must be of the correct intensity (how fast). duration (how long), frequency (how often) and it must be specific to the required goals. At present, we approach these four categories in the following manner.

\section{Frequency and duration}

Current evidence suggests that cardiac patients should train for between 3 to 5 hours a week (i.e. I hour, 3 to 5 times a week), depending on how hard they exercise.

\section{Intensity}

Undoubtedly the most critical decision concerns the intensity at which each cardiac patient should exercise. Because the severity of coronary heart disease differs in all patients, the intensity at which each is able to exercise safely will obviously vary. Thus the prescription of the training intensity must be carefully individualized for each patient. Figures $I$ and 2 illustrate one approach to this problem.

\section{TRAINING ZONE CONCEPT}

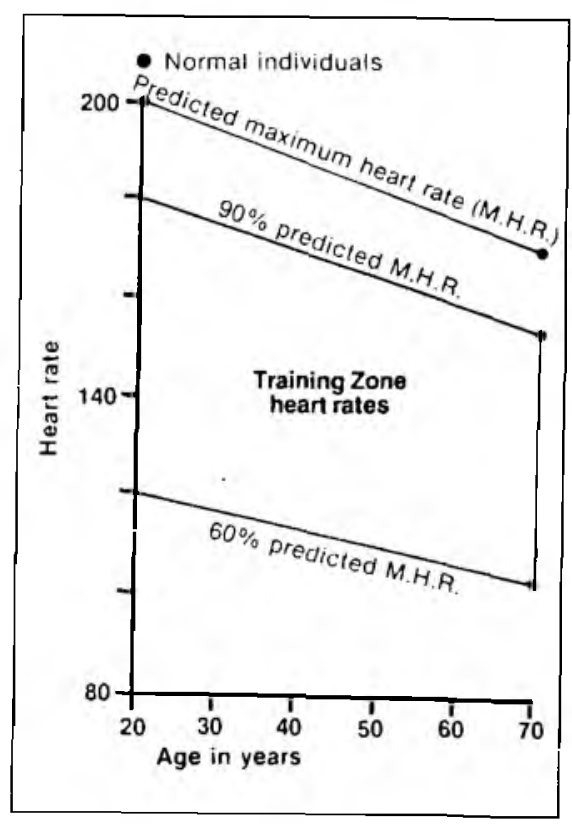

Fig. 1. With age, there is a predictable fall in maximum heart rates. To achieve an aerobic training effect, it is believed that the exercising heart rates should be between 60 and $90 \%$ of maximum. 
Figure I shows that with age there is a predictable fall in maximum attainable heart rate from a value of about 200 at age 20 , to about 150 at age 70 . It is also known that to achieve an aerobic training effect, the training intensity must be between 60 and $90 \%$ of the predicted maximum heart rate. Heart rates that fall between these two values constitute "training zone heart rates". In normal healthy individuals it is a simple matter to predict each individual's training heart rate zone on the basis of his age.

But in cardiac patients, without prior exercise testing, it is quite impossible to predict these training zone heart rates, because coronary heart disease has a totally unpredictable effect on the maximum achievable heart rate. Thus maximum heart rates in a 40 year old cardiac patient may. for example, be anything between 90 and 180 beats/min.

\section{SAFE EXERCISE INTENSITY FROM ECG RESPONSE}

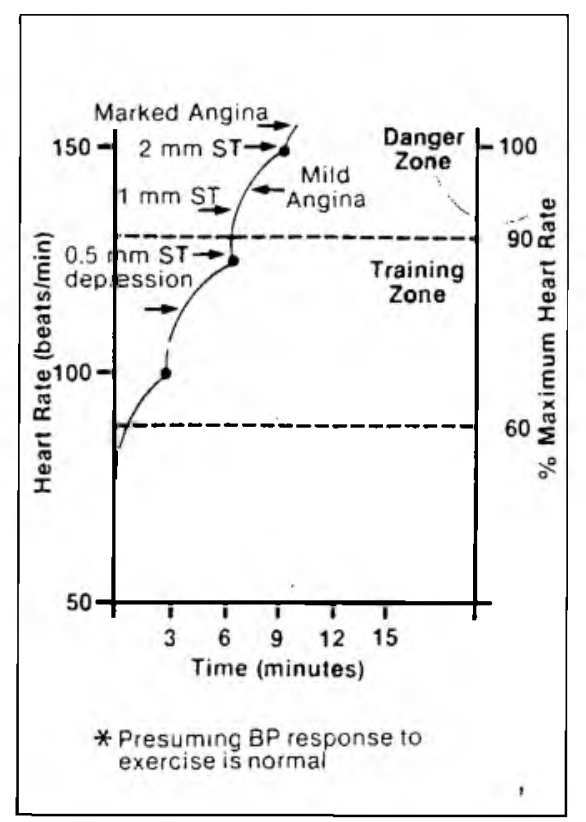

Fig. 2. This figure shows how the cardiac patient's electrocardiographic and symptomatic response to an exercise test is used to determine the intensity at which he can exercise. In this hypothetical example, mild angina pectoris and $2 \mathrm{~mm}$ electrocardiographic $\mathrm{ST}$ segment depression occurs at a heart rate of 150 beats $/ \mathrm{min}$.

By exercising at between 60 and $90 \%$ of this maximum heart rate (150 beats/ $\mathrm{min})$, not only will the patient's safety be assured, but the intensity will be sufficiently high to achieve a training effect.

Figure 2 shows how, from the results of an exercise test, the training zone heart rates can be established in the cardiac patient. In that figure, which is based on an hypothetical test, the electrocardiogram was monitored during a progressive treadmill exercise test consisting of 3 minute work stages. Blood pressure (not shown) was monitored every minute and in this hypothetical case, the response was normal, falling in the upper zone portrayed in Figure 3.

It will be noted that in the second exercise stage (between 3 and 6 minutes), electrocardiographic ST segment depression

\section{WORKLOADS}

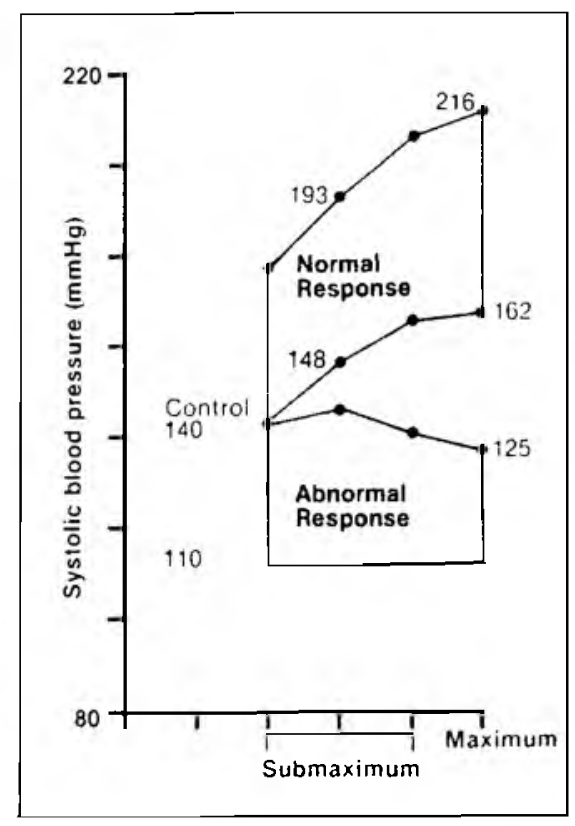

Fig. 3 During dynamic exercise of increasing intensity, systolic blood pressure should increase as shown in the upper shaded area of this figure. Failure of the systolic blood pressure to rise normally during a progressive exercise test indicates severely compromised heart function and is an absolute indication to terminate the exercise test without delay.

Data after Wolthuis et al, Circulation 1977, 55, 153-157.

of $0.5 \mathrm{~mm}$ is first noted at a heart rate of approximately 112 beats $/ \mathrm{min}$. This progresses to $1 \mathrm{~mm} \mathrm{ST} \mathrm{segment} \mathrm{depression}$ at a heart rate of about 135 beats/minute, at which point the patient complains of mild, but distinctive, angina pectoris. At a heart rate of 150 beats/minute, the ST segment depression equals $2 \mathrm{~mm}$ and shortly thereafter the patient complains of marked angina, and the test is terminated. (This illustration shows that ST-segment changes may, precede the onset of angina. Many authorities would advis that a stress test should be terminated when ST levels are depressed by $2 \mathrm{~mm}$.) From the results of this adequate, symptom-limited maximum exercise test, it is now possible to safely prescribe exercise for this patient.

Our approach is to prescribe exercise at up to $90 \%$ of the maximum heart rate measured during the treadmill test if the test failed to reveal any complications (abnormal blood pressure response; significant ST segment depression of 2 or more $\mathrm{mm}$, or angina pectoris). Alternatively, if any of these abnormalities do manifest during exercise, then the maximum allowable exercising heart rate is $90 \%$ of that heart rate at which these abnormalities appeared

It is essential for each patient to progress slowly up to an exercise intensity that elicits his maximum allowable heart rate. This is particularly necessary to prevent the development of orthopaedic problems. Therefore, for the first 2 weeks on the programme, patients exercise at only $70 \%$ of their maximum allowable heart rates. Thereafter, they are allowed to exercise at up to $80 \%$ of their maximum heart rate for a further three to six weeks, and only thereafter are they allowed to exercise at up to $90 \%$ of maximum. 
Patients are re-tested after 6 mont hs either if they develop symptoms during exercise or if their original test did not reveal any abnormalities, and the patient finds that he is persistently exercising at more than $90 \%$ of his maximum allowable heart rate.

It is our current experience. consistent with the published literature, that ST segment changes at a particular heart rate are not altered by training. Thus a patient whose initial test showed electrocardiographic ST segment depression at a particular heart rate will, after a training period, show the identical response either at the same heart rate, or a a lower rate (indicating coronary artery disease progression). Thus the patient whose previous exercise test was abnormal and who persistently exercises at a heart rate greater than his maximum allowable rate, is simply overdoing it, and must be advised to reduce his exercise intensity. But the patient who persistently exercises at more than his maximum allowable heart rate but whose previous test was normal may, on the basis of a repeat test, be allowed to increase his exercise intensity if, on the repeat test, he achieves a higher maximum heart rate without the development of any abnormalities.

\section{Patient monitoring during exercise}

Once the patient has been exercise tested and it has been established that there is nothing to contra-indicate exercise training, he or she may be admitted to a Rehabilitation Programme which should ideally be held three times a week. For reasons that will be discussed, most of the time allocated for exercise should be spent walking, jogging or cycling, with other less strenuous activities providing an occasional break in routine.

During each exercise session, careful attention is paid to the following:

- The patient's exercising heart rate is regularly checked. At first, heart rates are measured every few minutes but later, as the patient's ability to monitor his exercise intensity improves, heart rates are monitored only once every session. The pulse checks are essential to insure that the patient exercises at the appropriate intensity. Each patient is carefully instructed so that he knows what his maximum allowable heart rate is, and how he can measure his pulse. To re-inforce these practices, all patients are required to fill out an activity card at the end of each exercise session. The card includes information on resting heart rates and blood pressures, on exercising heart rates, on distance covered during exercise, on the presence of symptoms, and any medications that might have been taken.

- Abnormal heart rhythms must be constantly looked for by both patients and doctors. Patients are therefore told to report any cardiac rhythm abnormalities.

- All symptoms must be immediately reported. Our belief is that patients will develop warning symptoms and only if these symptoms are ignored, will problems develop. Symptoms such as excessive fatigue, general malaise and tiredness, and especially angina-type pain must be taken extremely seriously. They are an immediate indication to reduce the training load, and for further cardiac evaluation. - The patient is not allowed to exercise during or within one week of a pyrexial illness due to the possible, albeit low, risk of a fatal myocarditis (Kavanagh, T. and Noakes, T. D. (I979)).

Patients are also told that they must train regularly without peaks of activity, that they must avoid competition. that they must reduce their exercise training load when either ischaemic prodomata or mental tension and depression develop. It is our feeling that work tension and business stress, particularly when it involves travel, are important causes of transient exacerbation of symptoms. Smoking is absolutely prohibited because of its serious effect on patient prognosis (Mulcahy el al( 1977$)$ ), and particular attention is paid to patients with Type A personalities because they are notoriously difficult to control in the exercise rehabilitation setting. They are the ambitious, competitive, deadlinefighting characters who are over-eager to excel and to 'defeat' their disease (Kavanagh, T. and Noakes, T. D. (1979)). They will frequently exceed their exercise prescription and fail to report symptoms. Thus they need particular attention.

\section{THE EXERCISE MODE. WHY ONLY WALKING AND JOGGING?}

The question is frequently asked: Why is walking and jogging the most frequently prescribed exercise for the cardiac patient? There are various reasons for this.

First, arguably the most successful rehabilitation programme in the world, that developed by Kavanagh at the Toronto Rehabilitation Centre (Kavanagh, T. and Noakes, T. D. (1979); Kavanagh, T. (1976)) is based purely on walking and jogging. Yet it has one of, if not the highest exercise compliance rates of any rehabilitation programme in the world. Thus the major criticism against the use of walking/jogging, namely that it is "too boring" and that patients will not comply with the programme, has been disproved by the outstanding success of that programme.

Second, walking/jogging is non-competitive, its intensity can be self-controlled, it can be done anywhere, and does not require expensive equipment or, indeed much room. For example, some patients have even learned to jog in the narrow confines of hotel rooms whilst travelling.

Third, walking/jogging is the exercise mode most applicable to daily living. The patient can therefore relate the exercise he performs in the programme with the exercise requirements of his daily life. He soon learns what activities in his daily life he can do without limitation, and those in which he should be more cautious. Furthermore, because few adult South Africans ever do much walking/jogging. after only a few weeks' training most cardiac patients are able to achieve physical feats that they have not done since their childhoods. This becomes a strong motivational factor for further improvement.

Fourth, it seems that the optimum training effect and optimum psychological benefits result when the person does (fairly) hard, protracted physical effort.

It has been our experience that the feeling of physical achievement is far greater when more vigorous exercise, like jogging. is performed. Also we feel that there is a greater training benefit when a particular set of large muscle groups is persistently trained. In the short term. "entertainment activities" like volleyball, calisthenics and table tennis may be acceptable, but our interpretation is that these activities incur low rates of oxygen consumption (Fletcher, el al (1979)) and therefore probably produce little training benefit and provide little motivation for the patient to modify his lifestyle.

In the long term, the best hope for the cardiac patient would seem to be that he should become "addicted" to a physically-demanding activity which will encourage him to adopt a lifestyle associated with low coronary risk.

\section{ACKNOWLEDGEMENTS}

The Western Cape Cardiac Rehabilitation Programme is run under the auspices of the Southern African National Heart Foundation, whose financial support of this project is 
gratefully acknowledged. The Chris Barnard Fund has provided generous funding for the purchase of essential exercise testing equipment.

The programme is run by the author, in conjunction with

Dr. David Nathan FACC, Dr. Francis Thandroyen MRCP and Sister Thérese de Boer. Their enthusiasm and support is gratefully acknowledged, as is the help of the committee of the Cape Western Branch of the National Heart Foundation and that of Professor Brian Kennelly, who originated this project.

\section{References}

Borg, G. (1970). Perceived exertion as an indicator of somatic stress. Scand. J Rehabil. Med., 2, 92-98.

Cassem, N.H. and Hackett, T.P. (1977). Psychological aspects of myocardial infarction. Med. Clin. North Am., 61, 711-721.

Castellanet, M.J., Greenberg, P.S, and Ellestad. M.H. (1978). Comparison of ST segment changes on exercise testing with angiographic findings in patients with prior myocardial infarction. Am. J. Cardiol., 42, 29-35.

Clausen, J.P. (1976). Circulatory adjustments to dynamic exercise and effect of physical training in normal subjects and in patients with coronary artery disease. Prog. Cardiovasc. Dis., 18, 459-494.

Ferguson, R.J., Côté, P., Gauthier, P. and Bourassa, M.G. (1978). Changes in exercise coronary sinus blood flow with training in patients with angina pectoris. Circulation, 58, 41-47.

Fletcher, G.F., Cantwell, J.D. and Watt, E.W. (1979). Oxygen consumption and haemodynamic response of exercises used in training of patients with recent myocardial infarction. Circulation, 60, 140-144.

Irving. J.B. and Bruce, R.A. (1977). Exertional hypotension and postexertional ventricular fibrillation in stress testing. Am. J. Cardiol, 39, 849-851.

Irving, J.B., Bruce, R.A. and De Rouen, T.A. (1977). Variations in and significance of systolic pressure during maximal exercise (treadmill) testing. Am. J. Cardiol., 39, $841-848$
Kallio, V., Hämäläinen, H., Haḳkila, J. and Luurila, O.J. (1972). Reduction in sudden deaths by a multifactorial intervention programme after acute myocardial infarction. Lancet, 2, 1091-1094.

Kavanagh. T. and Noakes, T.D. (1979). Exercise prescription after myocardial infarction: an approach and a philosophy, Eds. Cohen, I., Beaton, G. R. and Mitchel. D. in: The South African Textbook of Sports Medicine, Wits. Univ.. Johannesburg, pp. 153-161.

Kavanagh, T. (1976). Heart attack? Counter attack! Van Nostrand Reinhold, Toronto.

Kavanagh, T., Shephard, R.J., Chisholm, A. W., Qureshi, S. and Kennedy, J. (1979). Prognostic indexes for patients with ischaemic heart disease enrolled in an exercisecentred rehabilitation programme. Am. J. Cardiol., 44, 1230-1240.

Mulcahy, R., Hickey, N., Graham, I.M. and Macaire, J. (1977). Factors affecting the five-year survival rate of men following acute coronary heart disease. Am. Hearr J., 93, 556-559.

Noakes, T.D. (1982). Criticisms àgainst exercise after heart attack: variations on an old theme? $S$. Afr. Med. J.

Paine, T.D., Dye, L.E., Roitmạn, D.I., Sheffield, L.T., Rackley, C.E., Russel, R.O. and Rogers, W.J. (1978). Relation of graded exercise test findings after myocardial infarction to extent of coronary artery disease and left ventricular dysfunction. Am. J. Cardiol., 42, 716-723.

Pollock, M.L. and Schmidt, D.H. (1979). Heart disease and rehabilitation. Houghton Mifflin, Boston.

Powles, A.C.P., Sutton, J.R., Wicks, J.R., Oldridge, N.B. and Jones, N.L.. (1979). Reduced heart rate response to exercise in ischaemic heart disease: the fallacy of the target heart rate in exercise testing. Med. Sci. Sporrs, 11, 227233.

Shephard, R.J. (1979). Cardiac rehabilitation in prospect, Eds. Pollock, M.L. and Schmidt, D.H., in: Heart disease and rehabilitation. Houghton Mifflin, Boston, pp. 521547.

Shaw, L.W. (1981). Effects of a prescribed supervised exercise program on mortality and cardiovascular morbidity in patients after myocardial infarction. The National Exercise and Heart Disease Project. Am. J. Carcliol. . 49, 39-46. 